\title{
Mechanical Behavior of Supporting Structure of Rectangular Deep Ventilation Shaft in Rail Transit
}

\author{
Jinke $\mathrm{Gu}^{1}$, Lin Huang ${ }^{1}$, Feng Qiu ${ }^{1}$, Xiaoguang Jin ${ }^{1 *}$ \\ ${ }^{1}$ School of Civil Engineering, Chongqing University, Chongqing, 400045, P. R. China
}

\begin{abstract}
In order to analyze the mechanical behavior of surrounding rock and initial support during shaft excavation and support process, reveal the law of stratum displacement, the stress characteristics of surrounding rock and the internal force of supporting structure during construction, this paper establishes a three-dimensional finite element numerical model relying on the construction process of a ventilation shaft in Chongqing Rail Transit. The results show that the stress of shotcrete, the bending moment of supporting structure, the axial force of bolt and the axial force of I-beam are all within the allowable range. The "S" shape bending occurs in the range of $60 \mathrm{~m} \sim 70 \mathrm{~m}$ for the axial force of bolt and cross brace I-beam. According to the results of model test, there is inflection point in the pressure distribution of rectangular deep ventilation shaft in rail transit, which provides a basis for the support design of deep ventilation shaft.
\end{abstract}

\section{Introduction}

At present, the design and calculation of supporting structure of rectangular ventilation shaft in urban rail transit are mostly based on the design method of deep foundation pit. At present, the depth of deep foundation pit is less than $40 \mathrm{~m} \mathrm{[1]}$, and the depth of ventilation shaft in mountain urban rail transit is more than $40 \mathrm{~m}$, some of which reach $100 \mathrm{~m}$. There are many studies on ventilation shaft and mining shaft in highway tunnel, but their shape is mainly circular [2-5]. At present, there are few studies on rectangular deep ventilation shaft in rail transit, and the lateral pressure of surrounding rock and the mechanical behavior of supporting structure of rectangular deep shaft are not clear, so further research is urgently needed.

Based on the construction process of a ventilation shaft in Chongqing Rail Transit, this paper studies the mechanical behavior of supporting structure of rectangular ventilation deep shaft. It provides a reference for the design and construction of similar projects.

Relying on the rectangular deep ventilation shaft, the well depth is $81.5 \mathrm{~m}$, the excavation length is $31.76 \mathrm{~m}$, and the width is $6.66 \mathrm{~m}$. The shaft is constructed by fullsection layered excavation and adopts composite lining structure. The lithology of the shaft site is filled with sand, sandstone, sandy mudstone, sandstone and sandy mudstone from top to bottom, with thicknesses of $9 \mathrm{~m}, 14$ $\mathrm{m}, 50 \mathrm{~m}, 8.5 \mathrm{~m}$ and $98.5 \mathrm{~m}$ respectively. The surrounding rock is basically graded IV. level. The initial support parameters are listed in Table 1.

Table 1. Initial support mode.

\begin{tabular}{|c|c|c|c|c|}
\hline Shotcrete & Anchor & Cross bracing & $\begin{array}{c}\text { Single layer steel } \\
\text { mesh }\end{array}$ & Depth \\
\hline \multirow{2}{*}{$\begin{array}{l}\text { C25 Early strength } \\
\text { concrete } 260 \mathrm{~mm}\end{array}$} & C22@1m×0.75m & 20a I-beam@2.25m & \multirow{2}{*}{ A8@200mm ×200mm } & $0 \sim 9 \mathrm{~m}$ \\
\hline & $\mathrm{C} 22 @ 1 \mathrm{~m} \times 1 \mathrm{~m}$ & 20a I-beam@3.0m & & $9 \sim 81.5 \mathrm{~m}$ \\
\hline
\end{tabular}

\section{Establishment of numerical model}

According to the actual size of the rectangular deep ventilated shaft, combined with the Saint-Venant principle, the length, width and height of the model are selected to be $180 \mathrm{~m}, 40 \mathrm{~m}$ and $180 \mathrm{~m}$, respectively. The numerical model is shown in Figure 1. There are 41565 hexahedral mesh elements and 35361 nodes. The load boundary condition only considers the initial stress state formed by gravity, without considering the stress history of surrounding rock. The displacement boundary conditions set corresponding normal displacement constraints on the edges and bottom of the numerical model, and the upper surface of the model is a free boundary. According to the geological survey and design data, the physical and mechanical parameters of rock and soil are listed in Table 2.

\footnotetext{
*Corresponding author: Jinxiaoguang@ $@$ cqu.edu.cn
} 


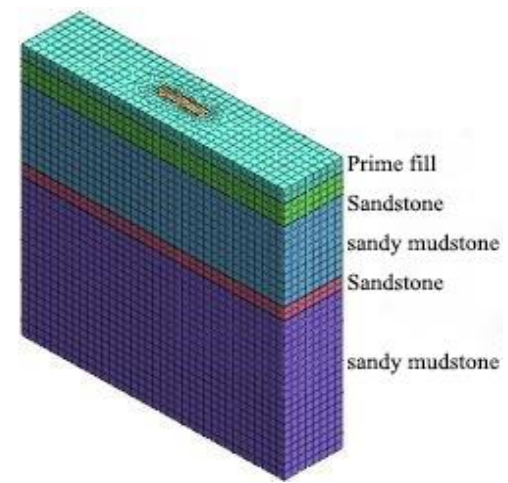

Figure 1. Numerical calculation model.

Table 2. Mechanical parameters of surrounding rock.

\begin{tabular}{cccccc}
\hline Lithology & $\begin{array}{c}\text { Severe } \\
\left(\mathrm{kN} / \mathrm{m}^{3}\right)\end{array}$ & $\begin{array}{c}\text { Internal Friction } \\
\text { Angle }\left(^{\circ}\right)\end{array}$ & $\begin{array}{c}\text { Cohesion } \\
(\mathrm{kPa})\end{array}$ & $\begin{array}{c}\text { Modulus of Elasticity } \\
(\mathrm{GPa})\end{array}$ & $\begin{array}{c}\text { Poisson's } \\
\text { Ratio }\end{array}$ \\
\hline Prime fill & 20.0 & 28 & 28 & 0.08 & 0.40 \\
Sandstone & 25.1 & 41 & 1800 & 4.88 & 0.22 \\
sandy mudstone & 25.6 & 32 & 700 & 2.38 & 0.34 \\
\hline
\end{tabular}

The ventilation shaft is excavated by full-section layered excavation method. The excavation depth of each layer is $3.0 \mathrm{~m}$. It is constructed by reverse construction method. After each layer of excavation is completed, the thickness of the shotcrete is $260 \mathrm{~mm}$, and the mortar anchor and the cross-section of the I-beam are applied until the excavation support is completed. Considering that it is impossible to apply single-layer steel mesh in the numerical model, the support stiffness of shotcrete and steel mesh is converted into equivalent support stiffness by using the principle of equivalent elastic modulus, that is, the elastic modulus of Shotcrete for initial support of shaft is equivalent elastic modulus. The supporting structure parameters used are shown in Table 3.

Table 3. Mechanical parameters of support structure.

\begin{tabular}{cccc}
\hline $\begin{array}{c}\text { Supporting } \\
\text { structure }\end{array}$ & $\gamma\left(\mathrm{kN} / \mathrm{m}^{2}\right)$ & $\mathrm{E}(\mathrm{GPa})$ & $v$ \\
\hline $\begin{array}{c}\text { Shotcrete } \\
\text { (slab } \\
\text { element) }\end{array}$ & 23 & 25.2 & 0.2 \\
\hline $\begin{array}{c}\text { Bolt (bolt } \\
\text { element) }\end{array}$ & 78.5 & 210 & 0.3 \\
\hline $\begin{array}{c}\text { 20a I-beam } \\
\text { (bar element) }\end{array}$ & 78.5 & 200 & 0.3 \\
\hline
\end{tabular}

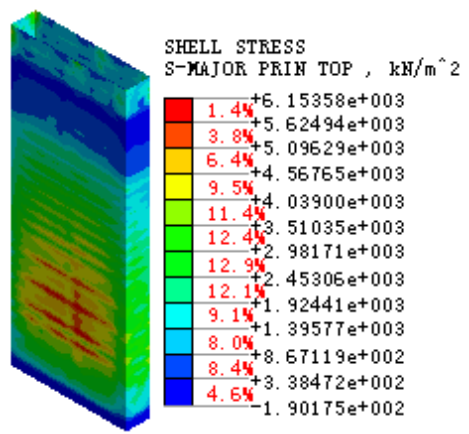

Figure 2. Maximum principal stress of shotcrete.

\section{Mechanical Behavior of Supporting Structure during Shaft Construction}

\subsection{Stress characteristics of surrounding rock}

After the completion of the shaft construction, the local maximum tensile stress of the supporting structure reaches $6.15 \mathrm{MPa}$ (figure 2), which exceeds the tensile strength of C25 concrete. During the actual construction of the shaft, the support should be strengthened by erecting steel frame, setting up double-layer steel mesh and increasing the thickness of shotcrete to avoid the tension damage of the initial supporting concrete. During the actual construction of the shaft, the support should be strengthened by erecting steel frame, setting up doublelayer steel mesh and increasing the thickness of shotcrete to avoid the tension damage of the initial supporting concrete.

After the completion of the shaft construction, the maximum compressive stress of the supporting structure is-3.07 $\mathrm{MPa}$ (figure 3), which does not exceed the compressive strength of C25 plain concrete $11.9 \mathrm{MPa}$.

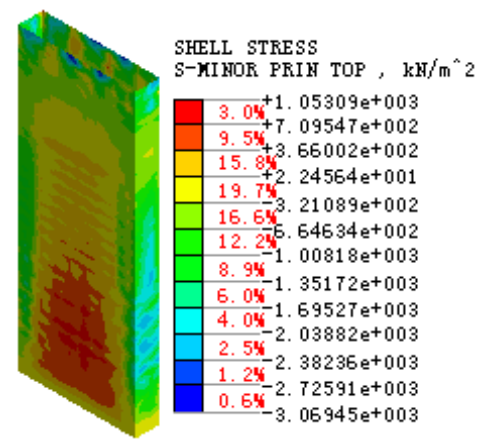

Figure 3. Minimum principal stress of shotcrete. 


\subsection{Bending moment of support structure}

In the process of shaft construction, due to the influence of spatial structure, the initial support of plate element will produce two directions of bending moment, vertical bending moment and transverse bending moment. Because the size of the long side is much larger than that of the short side, the ratio of length to width is close to 5 , and the short side is restrained by both ends, which is much smaller than the bending moment of the long side. Therefore, the long side bending moment of the shaft is selected for calculation. The variation of vertical bending moment along depth is shown in figure 4 . It can be seen that:

(1) The vertical bending moments in the long side of the shaft are mainly negative. The initial support of the shaft is mainly pulled in the inside of the pit, compressed in the outside, and the maximum bending moment in the inside is $254 \mathrm{kN} \cdot \mathrm{m}$; In the upper filling area, there is a small lateral tension in the initial support, and the maximum lateral tension moment is $286 \mathrm{kN} \cdot \mathrm{m}$. When the actual construction of the shaft reaches the position where the bending moment is larger, the support should be strengthened to avoid the cracking of the tension side caused by the excessive bending moment of the initial supporting concrete, which will affect the stability and safety of the shaft.

(2) There are many sudden changes in the vertical bending moment. The main reason for the analysis is that there is a steel support at the corresponding position, which acts like a local fixed end, thus causing a partial change in the local strength of the well wall and a sudden change in bending moment.

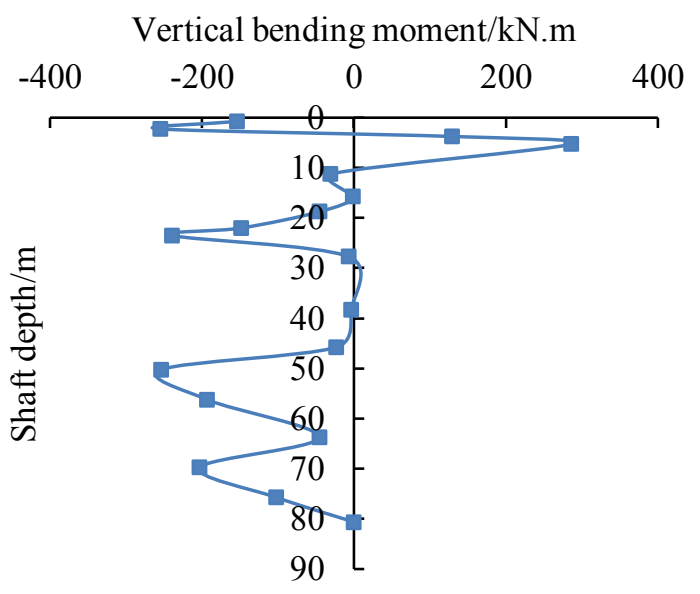

Figure 4. Curve of vertical bending moment along depth.

\subsection{Anchor axial force}

The horizontal displacement of the shaft is the middle position of each side, and the axial force data of the long and short side spans are extracted respectively, and the variation curve along the depth of the shaft is obtained as shown in figure 5 and figure 6.

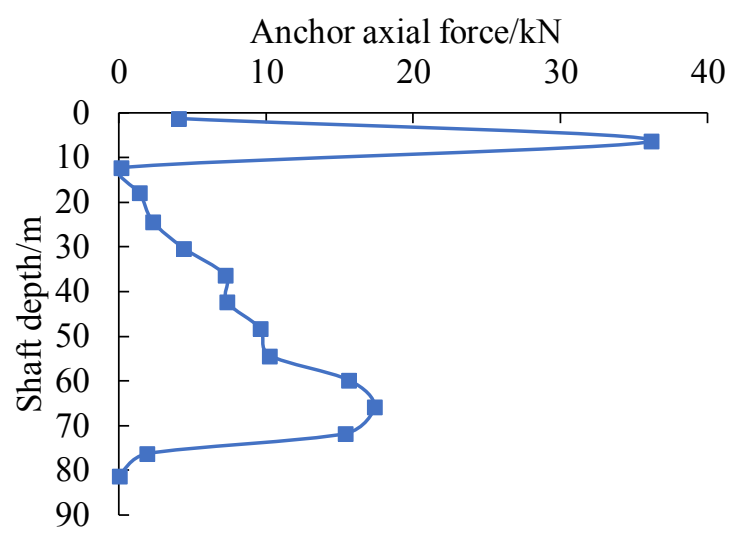

Figure 5. Curve of short side axial force along depth.

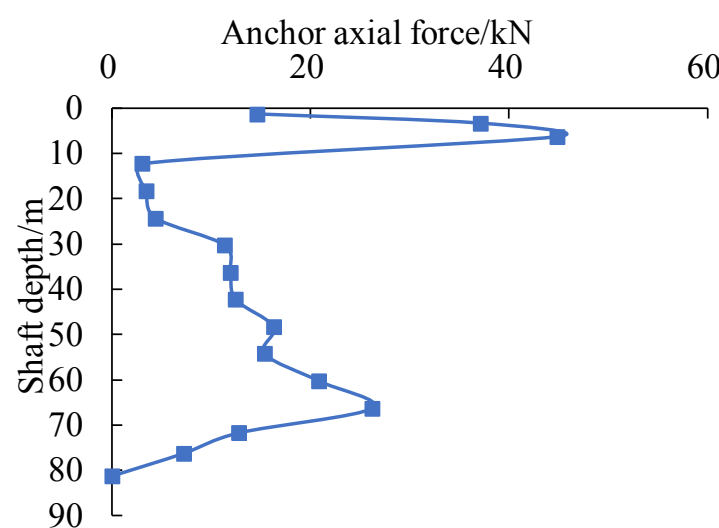

Figure 6. Curve of long side axial force along depth.

By analyzing figure 5 and figure 6 , the following conclusions can be drawn:

(1) Whether in the middle of long span or short span, the shape of the curve of axial force variation along the depth of the shaft is similar to that of horizontal displacement variation along the depth of the shaft at the corresponding position. Where the horizontal displacement is large, the axial force of the bolt is also large, which indicates that the magnitude of the axial force of the bolt is positively correlated with the horizontal displacement of the shaft.

(2) Where the axial force of anchor bolts in the middle span of long side and short side is larger, they occur in the upper plain fill layer and the middle and lower sandy mudstone layer of the shaft, which are also the places where the horizontal displacement of the shaft is larger. The maximum value appears near the maximum horizontal displacement of surrounding rock in the plain filling area of the upper part of the shaft. The maximum axial force of anchor rod in the middle of long span is 45 $\mathrm{kN}$, and that of anchor rod in the middle of short span is $36 \mathrm{kN}$.

\subsection{Horizontal support I-steel axial force}

In the short side direction of the parallel shaft, I-beam braces of 20a are set up, with three braces per floor and a transverse spacing of $7.8 \mathrm{~m}$. The axial force data of I-beam near the middle span of long side are extracted, and the variation curve along the depth of the shaft is obtained as shown in figure 7. 


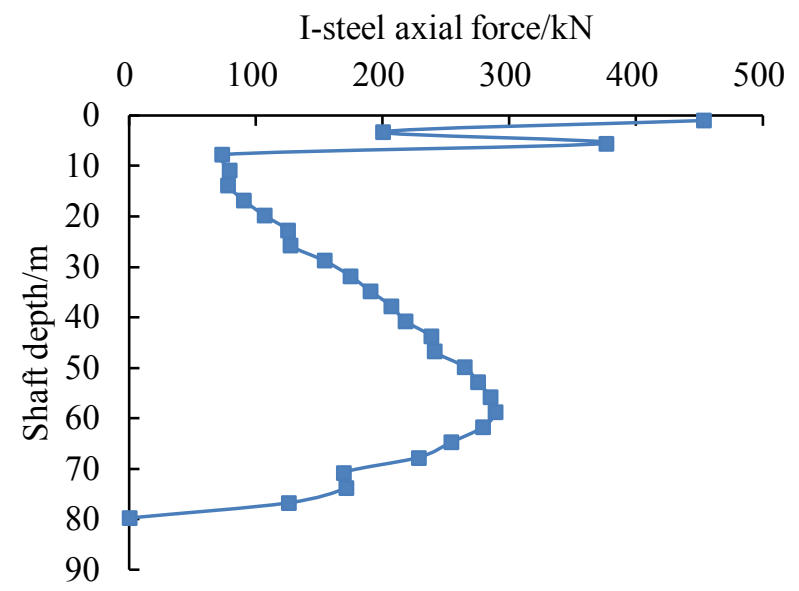

Figure 7. Curve of I-steel axial force along depth.

By analyzing figure 7 , the following conclusions can be drawn:

(1) The shape of the curve of the axial force of I-beam bracing along the depth direction of the shaft is similar to that of the horizontal displacement along the depth direction at the middle part of the long span at the corresponding position. Where the horizontal displacement is larger, the axial force of I-beam is larger, which indicates that the magnitude of the axial force of Ibeam is positively correlated with the displacement. Where the horizontal convergence of the shaft is greater,

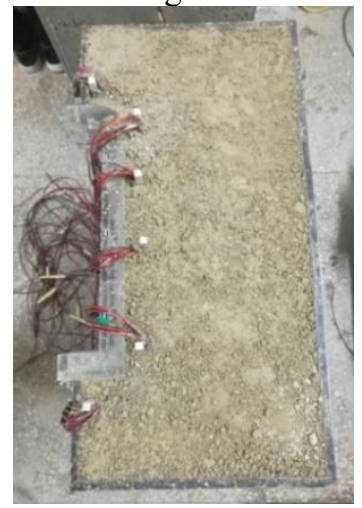

(a) the vertical view the more severe the I-beam is squeezed by the surrounding rock, the greater the force.

(2) Where the axial force of I-beam is large, it appears in the upper filling layer and the middle and lower sandy mudstone layers in the upper part of the shaft. These positions are also the places where the horizontal displacement of the shaft is large. The maximum value appears in the first layer of steel support at the top of the shaft. The maximum axial force of the I-beam is $453 \mathrm{kN}$. During the actual construction of the shaft, the monitoring and measurement of the corresponding position of the axial force should be strengthened to avoid the compression of the I-beam, thus ensuring the stability and safety of the shaft.

\subsection{Verification of inflection point distribution of surrounding rock pressure}

It can be seen from the vertical distribution characteristics of the axial deep anchor shaft axial force and the lateral Ibeam support axial force that the lateral pressure of the surrounding rock has a reverse bending point. In order to verify this point, a model experiment was carried out. The model test is shown in figure 8 . The monitoring points are shown in figure 9. The variation of lateral pressure distribution along depth is shown in figure 10 .

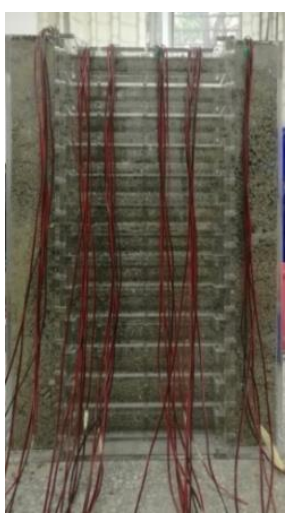

(b) the front view

Figure 8 . The vertical view and front view of model test.

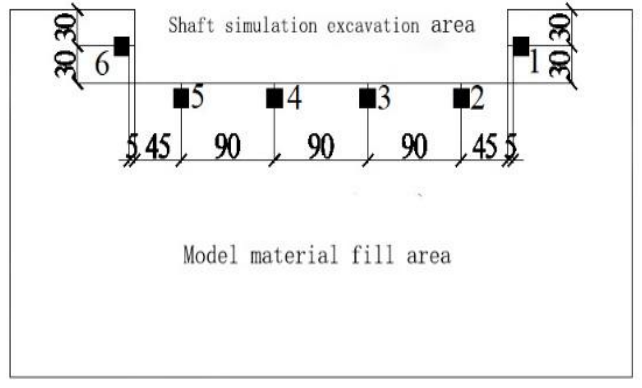

Figure 9. Side pressure monitoring points of surrounding rock.

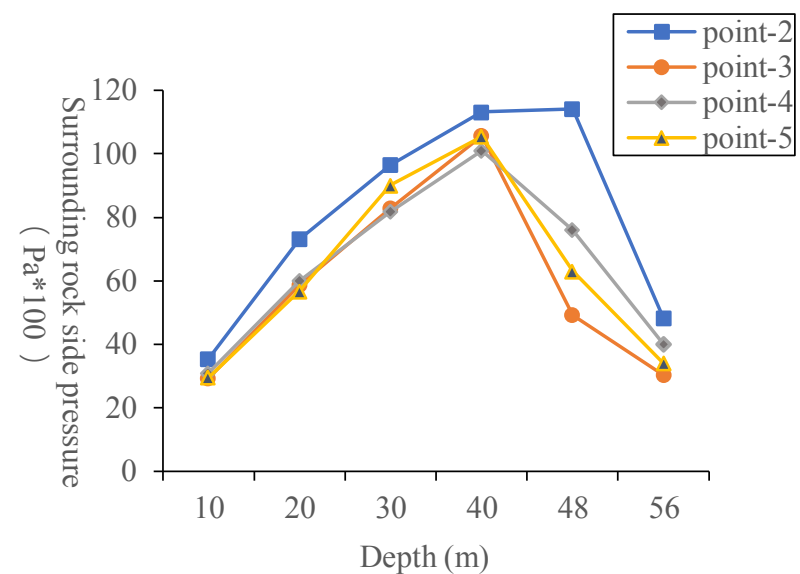

Figure 10. The diagram of surrounding rock lateral pressuredepth of the second model box. 
It can be seen that the lateral pressure of surrounding rock does not always increase with the increase of depth, which is different from the traditional calculation theory which assumes that the lateral pressure of surrounding rock increases linearly with the increase of depth.

In Figure 10, the pressure on the surrounding rock side of the deep test point is significantly smaller than that of the upper test point. For the $3 \mathrm{rd}$ and 4 th points, at $40 \mathrm{~m}$ depth, the pressure on the surrounding rock side is obviously reversed, that is, the pressure on the surrounding rock side will have an inflection point in the deep position of the shaft (the maximum position of the pressure on the surrounding rock side at the inflection point). Above the inflection point of lateral pressure of surrounding rock, the lateral pressure of surrounding rock of shaft conforms to the traditional theory of loose load calculation, and meets the characteristics of linear increase of lateral pressure of surrounding rock. Under the inflection point, the lateral pressure of the surrounding rock of the shaft will not increase, or even drop sharply. It provides a new basis for supporting design of deep ventilation shaft.

\section{Conclusions}

The vertical bending moment of the long side of the shaft is mainly negative, and the initial support of the shaft is mainly tensioned in the inside of the pit and compressed in the outside. When the shaft is actually constructed to the position with larger bending moment, the support should be strengthened to avoid the cracking of the tension side caused by the excessive bending moment of the initial supporting concrete. The variation characteristics of the axial force of bolt and cross brace Ibeam along the depth of the shaft are similar to those of horizontal displacement at the corresponding position along the depth of the shaft. Where the horizontal displacement is large, the axial force is also large. The magnitude of the axial force of the bolt and the cross brace I-shaped steel is positively correlated with the horizontal displacement of the shaft.

Three-dimensional finite element numerical simulation and model test show that the lateral pressure of the surrounding rock of the shaft does not increase linearly along the depth, but reaches inflection point at a certain depth.

\section{References}

1. Wenguang Fu, Zhiyin Yang. Deep classification of foundation pit and applicability of different deep support technologies [J]. Journal of Geotechnical Engineering, 2010,32 (S1): 99-103.

2. Pengyue Wang. Development and Prospect of Construction Technology of Super Large Diameter Deep Vertical Shaft [J]. Coal Engineering, 2018, 50 (06): 47-50.

3. Rong Zhou. Numerical simulation and Research on shaft construction process of Dapingli tunnel
[D]. Huazhong University of Science and Technology, 2007.

4. Liangping Du. Study on surrounding rock stability of large diameter deep shaft in Zhongnanshan Tunnel [D]. Tongji University, 2008.

5. Zhicheng Lu, Xumin Song. Theoretical prediction of surrounding rock stability and wall support thickness of kilometer vertical shaft in Yaojiashan Mine [J]. Journal of Taiyuan University of Technology, 2014, 45 (06): 807-812. 